\title{
Taguchi Yöntemi Kullanılarak Hafif Genleşmiş Kil Üretiminin Optimizasyonu
}

\author{
Özkan Küçük ${ }^{1 *}$, Yunus Uran² \\ ${ }^{1 *}$ Bilecik Şeyh Edebali Üniversitesi, Mühendislik Fakültesi, Metalurji ve Malzeme Müh. Bölümü, Bilecik,Türkiye, (ORCID: 0000-0002-4337-4454), \\ ozkan.kucuk@bilecik.edu.tr \\ 2 Bilecik Şeyh Edebali Üniversitesi, Lisanüstü Eğitim Enstütüsü, Bilecik, Türkiye, (ORCID: 0000-0002-4712-0849), M.Y.URAN@hotmail.com
}

(İlk Geliş Tarihi 21 Kasım 2021 ve Kabul Tarihi 25 Ocak 2022)

(DOI: 10.31590/ejosat.1026535)

ATIF/REFERENCE: Küçük, Ö., Uran, Y. (2022). Taguchi Yöntemi Kullanılarak Genleşmiş Kil Üretiminin Optimizasyonu. Avrupa Bilim ve Teknoloji Dergisi, (33), 1-9.

$\ddot{O} \mathbf{z}$

Genleşmiş kil agrega üretiminde, hangi parametrelerin etkili olduğunu bilmek ve bu parametrelerin genleşme üzerinde ne kadar etkili olduğunu belirlemek önemlidir. Bu çalışmada, hafif genleşmiş kil bilyelerinin üretiminin optimum şartlarının Taguchi yöntemi ile belirlenmesi incelenmiş olup, performans değeri olarak genleşme oranı ve pişme kaybı dikkate alınmıştır. Ayırca bulunan optimum şartlarda su emme oranı ve tane yoğunluğu da analiz edilmiştir. Çalışmada, parametre olarak organik madde yüzdesi $(0,1,2,3$ ve 4$)$, ön 1sitma sicaklığg $\left(150,200,300,400\right.$ ve $\left.500^{\circ} \mathrm{C}\right)$, ön 1sitma süresi $(1,3,5,7$ ve 9 dakika), sinterleme sicaklığ $1(1050$, 1100, 1150, 1175 ve $\left.1200^{\circ} \mathrm{C}\right)$ ve sinterleme süresi $(5,7,9,11$ ve 13 dakika) seçilmiş ve deneylerin tümünde tane boyutu $250 \mu \mathrm{m}$ altı olarak sabit alınmıştır. Buna göre optimum şartlar, organik madde yüzdesi \%3, ön 1sıtma sıcaklığ1 $150^{\circ} \mathrm{C}$, ön 1sıtma süresi 1 dakika, sinterleme sıcaklığ $1200^{\circ} \mathrm{C}$ ve sinterleme süresi 13 dakika olarak bulunmuştur. Bu şartlarda, tahmin edilen genleşme oranı \%4,34 olup, yapılan deneylerde \%4,32'lik bir değer, pişirme kaybı için ise tahmin edilen değer \%30,30 olup, yapılan deneylerde \%31,63'lük bir değer elde edilmiştir. Ayrıca parametrelerin çıktılar üzerindeki yüzde etkileri de hesaplanmıştır.

Anahtar Kelimeler: Hafif Genleşmiş Kil, Taguchi Metodu, Optimizasyon, Kil Bilyesi.

\section{Optimizing of Lightweight Expanded Clay Production By Using the Taguchi Method}

\begin{abstract}
In the production of lightweight expanded clay, it is important to know which parameters are effective and to determine the effect of these parameters on the expansion. In this study, the optimum conditions for the production of slightly expanded clay balls by the Taguchi method were investigated, and the expansion ratio and firing loss were taken into account as performance values. In addition, the water absorption rate and grain density were analyzed under optimum conditions. In the study, organic matter percentage $(0,1,2$, 3 and 4$)$, preheating temperature $\left(150,200,300,400\right.$ and $\left.500^{\circ} \mathrm{C}\right)$, preheating time $(1,3,5,7$ and 9 minutes), The sintering temperature $\left(1050,1100,1150,1175\right.$ and $\left.1200^{\circ} \mathrm{C}\right)$ and sintering time $(5,7,9,11$ and 13 minutes) were chosen and the grain size was fixed as below $250 \mu \mathrm{m}$ in all of the experiments. Accordingly, the optimum conditions were found to be organic matter percentage $3 \%$, preheating temperature $150^{\circ} \mathrm{C}$, preheating time 1 minute, sintering temperature $1200^{\circ} \mathrm{C}$ and sintering time 13 minutes. Under these conditions, the estimated expansion rate is $4.34 \%$, a value of $4.32 \%$ in the experiments, the estimated value for the cooking loss is $30.30 \%$, and a value of $31.63 \%$ was obtained in the experiments. In addition, the percentage effects of the parameters on the outputs were calculated.
\end{abstract}

Keywords: Lightly Expanded Clay, Taguchi Method, Optimization, Clay Ball.

\footnotetext{
*Sorumlu Yazar: ozkan.kucuk@bilecik.edu.tr
} 


\section{Giriş}

Hafif malzemelerin içerisinde basınç mukavemeti en yüksek olanı, genleştirilmiş kilden üretilen hafif yapı malzemesidir. Bazı kil, killi şist ve şeyllerin sinterleşme süreci hızlı olur ve 1100$1300^{\circ} \mathrm{C}$ derecelere kadar 1sıtıldığında genleşip hacim artışına uğrarlar. Bu özellikleri taşıyan killi şist, kil ve şeyllere genel olarak genleșen killer denilmektedir. Genleştirilmiş kil elde etmek için hammadde olarak; kumlu kil (Lem, mil), erken sinterleşen kil, killi şist ve şiferton yaygın olarak kullanılmaktadır. Genleştirilmiş kil, dünya piyasasında günümüzde Leca, Liapor ve Keramzit tanımlamaları ile de anılmaktadırlar. Türkiyede ise Lecat olarak isimlendirilmiştir. Şekil 1'de genleştirilmiş kil agregasından örnek gösterilmiştir (Güneş, 2019).

Hafif genişletilmiş kil agregası (LECA), kireç içermeyen veya çok az içerikli özel plastik kilden üretilir. Kil kurutulur, 1sitılır ve döner firınlarda $1100-1300{ }^{\circ} C^{\prime}$ de yakılır. LECA, firın dairesel hareketi nedeniyle neredeyse patates şeklinde veya yuvarlak şekilli, tek tip gözenek yapısına sahip gözenekli seramik üründür. LECA'daki çok sayıda küçük, hava dolu boşluk, hafiflik, termal ve ses yalıtımı özelliklerini verir(Rashad, 2018). Genleştirilmiş hafif kil agregasının üretilmesi 1917 yılında Kansas City'de başlamış olup, ilk standartlara girişi Amerika Birleşik Devletlerinde, sonra da Avrupada olmuştur. Kil bilyeleri yapılarda 1s1 ve ses yalıtımı, toprak basıncinı azaltma, drenaj, dolgu malzemesi olarak, topraksız tarımda, seracılıkta ve peyzaj uygulamalarında tercih edilen bir malzemedir. Genleşmiş kil tanelerinin büyük oranda hava boşluğu içerdiğinden, toprağın havalanmasını ve su geçirgenliğini yüksek olmasını sağlar. Buharlaşma ile su kayıplarını azaltır. Hastalık taşımaz, barındırmaz. $\mathrm{pH}$ değeleri $6.5<\mathrm{pH}<8.5$ aralığında olduğundan dolayı, bitkiler için uygun bir gelişme ortamı sağlar(LECAT, 2021).

Genleşen killer, 1sı ile işlem gördüklerinde, gaz çıkışı ile birlikte hacimleri 5 - 6 kat artar. İçerdikleri gazların çıkışıyla birlikte, yüzeylerinde sinter kabuk oluşmakta, çıkan gazlar bünyede tutulmakta ve gözenekli, hafif, sert ve cürufumsu bir yapıya dönüşmektedirler(Özgüven, 2009).

Mineralojik bileşimin en önemli değeri, 1sıl işlemin ana aşamalarında faz dönüşümleri de dahil olmak üzere, genleşmiş kilin yap1 oluşumunun karmaşık fiziko kimyasal sürecini önceden belirlemesi gerçeğinde yatmaktadır. Kimyasal bileşim esas olarak kil hammaddelerinin mineralojik bileşimine bağlıdır. Bu nedenle, her bir bileşenin içeriğinin sınırlarını ve bunların genleşen ve genleşmeyen kil hammaddelerinin yanı sıra değişen derecelerde genleşmeye sahip hammaddelerin oranlarını belirlemek önemlidir.(Onatskiy, 1987)

Günümüzde, hafif malzemelerin farklı ticari ve endüstri alanlarında tercih edilmesi her geçen gün yaygınlaşmaktadır. İnşaat sektöründe hafif ve gözenekli malzemeler, genellikle hafif yapı elemanlarının imalatında kullanılmaktadır. Ancak, kimyasal bileşimleri ve yapısal form özelliklerinden dolayı, inşaat endüstrisinde farklı alanlarda ve amaçlarda kullanılmaktadır. Mesela, avrupada bir konutun 1sitma maliyeti bize göre 3 kat daha azdır. Bunun nedeni yapılarda hafif yap1 malzemesi kullanılmasıdır. Hafif malzemelerin yalıtım özellikleri çok iyi olduğundan enerji tasarrufu sağlamaktadır.(Güneş, 2019)
Dünyada, genleşen kilden hafif malzeme üreten fabrikaların sayısında ve üretiminde düşüşler görülmesine rağmen, depreme dayanıklı binaların inşası ve enerji tasarrufu amacıyla gelecekte ülkemizin bu konuda bazı çalışmalar yapmalıdır. Türkiye'de genleşen kil rezervleri oldukça çok bulunmaktadır. Bu nedenle, ülkemizin kil rezevleri potansiyeli araştırılmalı, genleşme özellikleri analiz edilmeli, yapısal özellikleri ve endüstriyel olarak kullanılabilirlikleri araştırılmalıdır(Güneş, 2019). Günümüzde Bilecik ilimizin Söğüt ilçesinde genleştirilmiş kil üretimi yapan bir işletme faliyette bulunmaktadır.

Genleşmiş kil agregaların üretimi, teknik özelliklerinin karşılaştırılması ve yapı malzemesi olarak kullanımı üzerine literatürde birçok çalışma yapılmıştır.

Genişletilmiş kil agrega üretimi için etkin parametrelerin incelenmesi üzerine yapılmış bir çalışmada, farklı parametrelerin üretimi nasıl etkilediğini belirlemek için üç ayrı alandan örnekler kullanılarak genleşme testleri yapılmıştır. Genleşme testlerinde parametre olarak kil tane boyutu, pelet boyutu, firın sıcaklığg ve pişirme süresi seçilmiştir. Üretim üzerindeki etkileri ayrı ayrı kanıtlanmıştır. Kil boyutunun küçültülmesinin genleşme üzerinde olumlu, pelet boyutunun küçültülmesinin ise olumsuz yönde etkilediği tespit edilmiştir. Ayrıca fırın içindeki sıcaklık ve kilin fırında kalma süresinin de elde edilen agrega kalitesi için kritik değerler olduğu belirtilmiş ve optimum üretim için şartlar detaylı olarak anlatılmıştır(Ozguven \& Gunduz, 2012). Arı̈̈z ve arkadaşları (Arıöz, 2007) yapmış olduğu bir çalışmada, tuğla ve kiremit yapımında kullanılan kilin kömür ile farklı oranlarda karıştırılıp $1000-1200^{\circ} \mathrm{C}$ arasında ki sıcaklıklarda 1 sıl işleme tabi tutulması sonucu hafif, genleştirilmiş kil agregaları üretmişler, sonrasında agregaların kitlesel yoğunluk ve su emme özelliklerini belirlemişlerdir. Isıl işlem sıcaklığının ve kömür katkısı miktarının üretilen agregaların özellikleri üzerindeki etkileri incelenmiştir. Yapılan diğer bir çalışmada (L. Gündüz, Kalkan, Ş. O. \& Özgüven, A. , 2020) genleşen kil olarak değerlendirilebilecek en önemli sahalardan biri olan AnkaraKalecik kil sahasının detaylı arazi ve laboratuvar çalışmaları ile endüstriye kazandırılması amaçlanmış ve katkısız genleştirme deneyleri sonucunda genleşme oranı 6,3 ve agrega birim hacim ağırlığı $291 \mathrm{~kg} / \mathrm{m}^{3}$ olan çok kaliteli bir genleşmiş kil agregası üretiminin mümkün olduğu iddia edilmiştir.

Genleştirilmiş kil agregası ile farklı çimento dozajlarında taşıyıcı hafif beton üretim olanakları ve betonun mekanik ve fiziksel özelliklerine etkisinin araştırıldığı bir çalışmada, doğal kumun ve genleştirilmiş kil agregasının kullanıldığı beton karışımları tasarlanmıştır. Genleştirilmiş kil agregası ile 1,7 $\mathrm{kg} / \mathrm{m}^{3}$ gibi düşük bir yoğunluğa sahip, basınç dayanımı 41,27 $\mathrm{MPa}$ olan taşıyıcı hafif beton elde etmenin mümkün olduğu belirlenmiştir. Üretilen hafif beton karışımlarında $450 \mathrm{~kg} / \mathrm{m}^{3}$ çimento dozlu betonların en yüksek basınç dayanımı değerlerine sahip olduğu bulunmuştur(Subaşı, 2009). Yapılan bir araştırmada, genleşmiş kil agregaları ile tasarlanmış geleneksel ve hafif yapı betonları arasındaki dayanım ve elastik özellikleri karşılaştırılmıştır(Dilli, Atahan, \& Şengül, 2015). Genleşmiş kil agregası ve silis dumanının hafif betonun özellikleri üzerindeki etkisinin araştırıldığı bir çalışmada, araştırmacılar (Ahmad, Chen, \& Farasat Ali Shah, 2019) 1s1 yalıtımı, 1sıl kütle ve yapı malzemesi olarak kullanılacak, kendiliğinden akışlı ve enerji verimli hafif agregalı köpük betonun (LAFC) formülasyonu üzerinde yoğunlaşmışlardır.

Bir yapı malzemesi olarak hafif genleşmiş kil agregası hakkında yapılan bir araştırmada, geleneksel çimento esaslı 
malzemelerde ve ayrıca inorganik polimerlerde (jeopolimerler) yapı malzemelerinin bir parçası olarak kullanılmasına odaklanan daha önce yapılmış çalışmalar hakkında bilgi verilmiştir. Ayrıca, LECA beton ve harcının bazı özelliklerini değiştirmek için eklenen çeşitli malzemeler hakkında bilgi verilmiş ve raporlanmıştır(Rashad, 2018). Piero vd. kendiliğinden şişmeyen killerden hafif beton için genleşmiş kil agrega üretimi ile ilgili bir çalışma yapmışlardır(Pioro \& Pioro, 2004). Genleşmiş kil agregalı kendiliğinden yerleşen hafif beton üretiminin incelendiği bir araştırmada, hafif agregalı betonun (SCLC) kendi kendine yerleşebilirliği analiz edilmiş ve formülasyonu için izin verilen sınırlar önerilmiştir. SCLC'nin normal titreşimli hafif betona göre daha iyi performans gösterdiği bulunmuştur.(Bogas, Gomes, \& Pereira, 2012)

Genleşmiş kilin kullanıldığı diğer bir incelemede, genleşmiş kil granüllerinin birleştirilmiş gözenekli örneklerinin akustik ve akustik olmayan özelliklerinin sistematik bir çalışması sunulmuş ve parçacık boyutunun konsolide genleşmiş killerin akustik performansı üzerindeki etkisi deneysel ve teorik olarak araştırılmıştır(Vašina, Hughes, Horoshenkov, \& Lapčík, 2006).

Nkansah vd. PAH'ların (fenantren, floranten ve piren) sudan uzaklaştırılması için bir sorbent olarak hafif genişletilmiş kil agregasının (LECA) kullanımını araştırmışlardır. Araştırmacılar LECA'nın, sulu PAH'ların uzaklaştırılması için alternatif bir yöntem olarak kullanılabileceğini belirtmişlerdir(Nkansah, Christy, Barth, \& Francis, 2012).

Genleştirilmiş killer yapay bir madde olup, doğada genleşmiş halde bulunmazlar. Doğada bulunan her kil genleşmez. Genleşen kil üretmek için kullanılan ham maddeler erken sinterleşen kil, kumlu kil, killi şist, şeyl ve şifertondur(Devecioğlu, 2012). Ayrıca, genleşen kil yapımı sırasında, genleşmeyi arttırmak ve hızlandırmak için, motorin, kok kömürü, alçı, pirit, limonit, kireç gibi maddeler katılmaktadır(L. Gündüz, Şapçı, N., Bekar, M., 2006).

Yapmış olduğumuz mevcut çalışmamızda katkı maddesi olarak organik bir madde kullanılarak üretilen genleşmiş kil bilyelerinin, genleşme oranı ve pişme kaybı için optimum şartları belirlenerek, bu şartlardaki tane yoğunluğu ve su emme oranı da tespit edilmiştir. Tüm bu optimizasyon işlemlerinde Taguchi yöntemi kullanılmıştır. Yapılan literatür incelemesinde, genleşmiş kil üretiminin optimizasyonunda Taguchi yönteminin kullanıldığı bir çalışmaya rastlanmamıştır. Dolayısıyla bu çalışma bu açıdan bir ilk olduğu ve bundan sonra yapılacak optimizasyon çalışmalarına 1şık tutacağı kanaatindeyiz.

\section{Materyal ve Metot}

\subsection{Materyallerin Hazırlanışı}

$\mathrm{Bu}$ çalışmada kullanılan kil örnekleri, Söğüt Toprak Madencilik A,Ş, şirketine ait kil ocağından temin edilmiştir. Kullanılan kilin kimyasal analizleri XRF cihazı ile yapılmış olup Tablo 1 de ve XRD grafiği ise şekil 1 de verilmiştir.
Tablo 1. Çalışmada Kullanılan Kil’in Kimyasal Analizi (Table 1. Chemical Analysis of Clay Used in the Study)

\begin{tabular}{|l|l|}
\hline Bileşik & Yüzde (\%) \\
\hline Ateşte kayıp: LOI & 6,387 \\
\hline $\mathrm{NiO}$ & 0,043 \\
\hline $\mathrm{CuO}$ & 0,026 \\
\hline $\mathrm{BaO}$ & 0,402 \\
\hline $\mathrm{Fe}_{2} \mathrm{O}_{3}$ & 5,601 \\
\hline $\mathrm{ZrO}_{2}$ & 0,048 \\
\hline $\mathrm{CaO}$ & 2,407 \\
\hline $\mathrm{ZnO}$ & 0,024 \\
\hline $\mathrm{SrO}$ & 0,015 \\
\hline $\mathrm{TiO}$ & 1,292 \\
\hline $\mathrm{Al}_{2} \mathrm{O}_{3}$ & 16,885 \\
\hline $\mathrm{SiO}_{2}$ & 59,966 \\
\hline $\mathrm{MnO}$ & 0,128 \\
\hline $\mathrm{MgO}_{\mathrm{K}_{2} \mathrm{O}}$ & 1,501 \\
\hline $\mathrm{Na}_{2} \mathrm{O}$ & 1,438 \\
\hline $\mathrm{P}_{2} \mathrm{O}_{5}$ & 3,362 \\
\hline $\mathrm{SO}_{3}$ & 0,343 \\
\hline
\end{tabular}

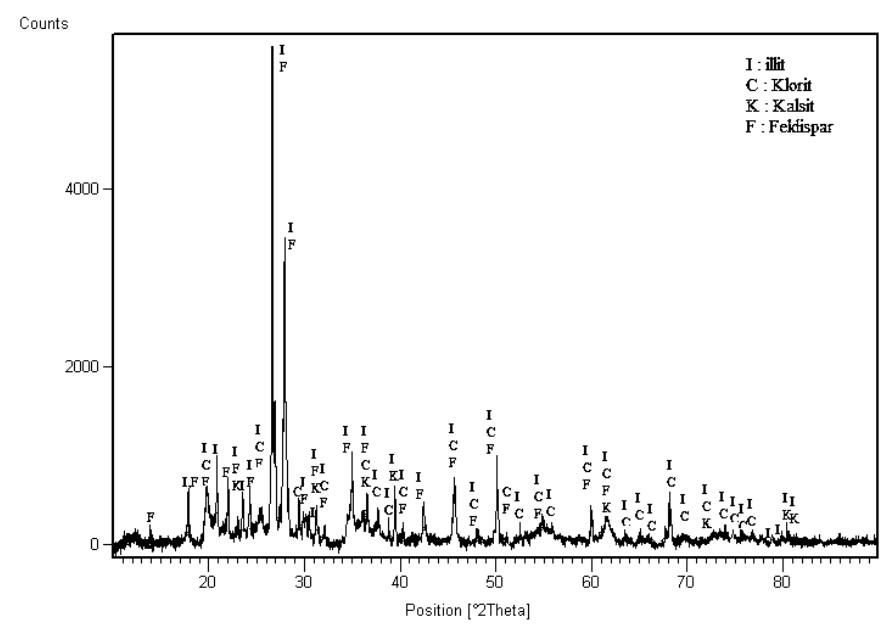

Şekil 1. Çalışmada Kullanılan Kil'in XRD Grafiği (Figure 1. XRD Graph of Clay Used in the Study)

Kil numunesi önce etüvde kurutulmuş ve 250 mikron altında olacak şekilde halkalı öğütücüde öğütülmüştür. Ayrıca organik madde olarak kullanılan katkı maddesi de aynı şekilde halkalı öğütücüde 250 mikron alına düşürülmüştür. Kil ve organik madde belli oranlarda \%23 rutubet içerecek şekilde karıştırılmış ve 5 ayrı karışım hazırlanmış olup, Tablo 2 de verilmektedir.

Tablo 2. Kil ve Organik Madde Karışım Oranları (Table 2. Clay and Organic Matter Mixing Ratios)

\begin{tabular}{|l|l|}
\hline 1.KARIŞIM & $\% 100 \mathrm{Kil}+\% 0$ Organik Madde \\
\hline 2.KARIŞIM & $\% 99 \mathrm{Kil}+\% 1$ Organik Madde \\
\hline 3.KARIŞIM & $\% 98 \mathrm{Kil}+\% 2$ Organik Madde \\
\hline 4.KARIŞIM & $\% 97 \mathrm{Kil}+\% 3$ Organik Madde \\
\hline 5.KARIŞIM & $\% 96 \mathrm{Kil}+\% 4$ Organik Madde \\
\hline
\end{tabular}


Daha sonra bu karışımlar kullanılarak $8 \mathrm{~mm}$ lik peletler oluşturulmuştur. $\mathrm{Bu}$ oluşturulan peletler farklı sıcaklık ve sürelerde önce kurutma işlemine tabi tutulmuş, ardından sinterleme işlemi yapılarak hafif genleşmiş kil üretimi tamamlanmıştır.

Genleşmiş kil bilyesi üretim aşamalarını gösteren akım şeması şekil 2 de ve tüm deneylerin sonucunda üretilen killer ise şekil 3 de verilmektedir.

Elde edilen genleşmiş kil numunelerinde tane yoğunluğu, pişme kaybı, genleşme oranı ve su emme oranı analizleri yapılmıştır. Daha sonra elde edilen değerler kullanılarak, optimum parametre seviyeleri Taguchi Metodu ile tespit edilmiştir.

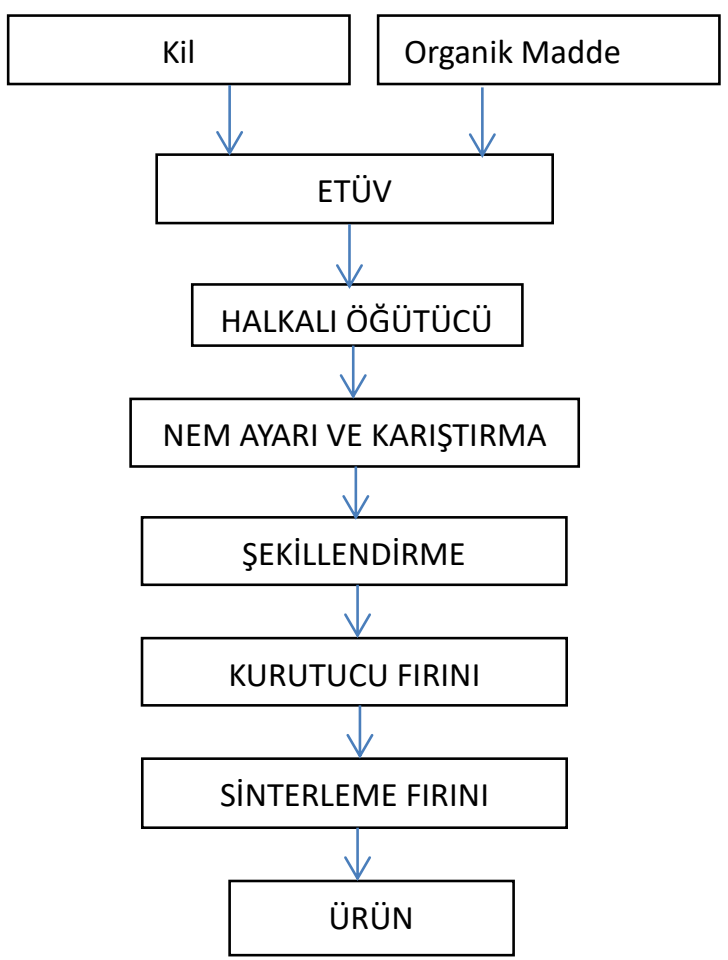

Şekil 2. Genleştirilmiş Kil Bilyesi Üretimi Akım Şeması (Figure 2. Expanded Clay Ball Production Flow Chart)

Numunelerin tane yoğunlukları Arşimet prensibine göre, piknometre kullanılarak ölçülmüş ve aşağıdaki formülden hesaplanmıştır.

$\rho=\frac{C-A}{[B+(C-A)]-D}$

Burada; A: piknometrenin boş ağırlığı, B: su dolu piknometrenin ağırlı̆̆ $1, \mathrm{C}$ : Piknometre + numune ağırlı̆̆ $1, \mathrm{D}$ : piknometre + su + numune ağırlı̆̆ı' dır.

Herbir sıcaklıktaki numuneler için \%genleşme miktarı ise aşağıdaki formülden hesaplanmıştır.

$\%$ Genleşme $=\left(\frac{R 1 / 2}{R 2 / 2}\right)^{3}$

Burada R1: Peletlerin firına girmeden önceki çap1, R2: Peletlerin şişme sonrası çapı'dır.

Pişme Kaybı,
$\%$ Pişme Kaybl $=\frac{m-m_{1}}{m} \times 100$

formülü ile hesaplanmıştır. Burada; m, fırına konmadan önce ham peletlerin kütlesi ve $\mathrm{m}_{1}$ firından çıkartılan genleşmiş kil soğutulduktan sonrakikütlesi'dir.

$\mathrm{Su}$ emme oranının (W) hasaplanmasında, önce kuru genleşmiş kil numuneleri tartılmış $\left(\mathrm{M}_{1}\right)$, daha sonra genleşmiş kil numunesi 24 saat suya daldırılıp bekletilmiş ve tekrar tartılmıştır $\left(\mathrm{M}_{2}\right)$. Su emme oranı (W), 24 saatlik daldırmadan sonra, su emme yüzdesi olarak aşağıdaki formülden hesaplanmıştır.

$W=\frac{100 \times\left(M_{2}-M_{1}\right)}{M_{1}}$

\subsection{Taguchi Metodu}

Endüstriyel süreçlerin optimizasyonunda, iyi planlanmış ve analiz edilmiş ön üretim deneyleri, ürünlerin kalitesini iyileştirmede ve maliyeti en aza indirmede, analizi sağlıklı yapabilmek için önemli katkı sağladığından dolayı istatistiksel deney tasarımları kullanılmaktadır. Zaman alıcı ve maliyetli olan klasik deney tasarımında; bir faktörün etkisi incelenirken, incelenen faktör dişındaki tüm faktörler sabit tutulup, sadece araştırılan faktör değiştirilmektedir. Oysa, istatistiksel deney tasarımında, birçok faktörün aynı anda sistematik olarak değişimi sözkonusudur. Faktörlerin etkileri iyi bir şekilde incelendiğinde, süreçin kontrolü için uygun adımlar atılabilir(Şirvanc1, 1997). İstatistiksel deney tasarım yöntemlerinden biri olan Taguchi Yöntemi, en az deney yaparak maliyetleri en düşük seviyede tutma prensibine dayanan bir yöntemdir(Taguchi, 1987). Bu yöntemin diğer istatistiksel deney tasarım yöntemlerinden farkı; bir deneyi etkileyen parametreleri, kontrol edilebilen ve kontrol edilemeyen olmak üzere iki grupta incelenmesi ve çok sayıda parametreyi ikiden fazla seviyede incelemeye imkân sağlamasıdır. Genellikle ürün veya sürecin her birinin performans karakteristiği nominal değer veya hedef değere sahip olmalıdır. Amaç, bu hedef değer etrafindaki değişkenliği azaltmaktır. Deneysel verilerden belirlenecek optimum çalışma şartları, farklı ortamlarda veya farklı zamanlarda, her zaman aynı veya birbirine yakın performans değerini verebilmelidir. Bunun için kullanılacak optimizasyon kriteri, Taguchi'ye göre performans istatistiğidir. Parametrelerin optimum şartlarının bulunmasında aşağıdaki performans istatistiği formülleri kullanılmaktadır(Küçük, 2005).

Daha büyük daha iyi;

$S N_{L}=-10 \log \left(\frac{1}{n} \sum_{n=1}^{n} \frac{1}{y^{2}}\right)$

Daha küçük daha iyi;

$S N_{S}=-10 \log \left(\frac{1}{n} \sum_{n=1}^{n} y^{2}\right)$

Burada n: deney tekrar sayısı, y: parametrenin deneysel olarak bulunan değeridir(burada y: genleşme oranı veya pişme kaybı vs. dir). Ĕger bir araştırmada, hadef maksimum değere ulaşmaksa, $\mathrm{SN}_{\mathrm{L}}$ değerini maksimum yapan parametre seviyeleri optimumdur. Eğer amaç minimum değeri yakalamaksa SNs'yi maksimum yapan parametre seviyeleri optimumdur (Montgomery, 1991). Taguchi yönteminde tespit edilen optimum çalışma şartlarını veren performans değeri, 
$\mathrm{Y}_{\mathrm{it}}=\mu+\mathrm{X}_{\mathrm{i}}+\mathrm{e}_{\mathrm{i}}$

eşitliği yardımı ile tahmin edilir. Burada $\mathrm{Y}_{\mathrm{it}}$ : i. deneyin tahmin edilen performans değeri, $\mathrm{X}_{\mathrm{i}}$ : i. deneyde kullanılan parametre seviyelerinin toplam etkinlik boyutu, $\mu$ : ortalama ve $e_{i}$ : deneysel hatadir.

Eşitlik 73, ilave modelin uygun olup olmadığını belirlemek için deneysel verileri kullanarak hesaplanan bir tahmindir. $\mathrm{Bu}$ yüzden tahmini hata için güven sınırları belirlenmelidir(Phadke, 1989). Tahmini hata, gözlenen $Y_{\text {it }}$ ile tahmin edilen $Y_{\text {it }}$ arasındaki farktır. Tahmini hata için güven aralığı (Se) aşağıdaki eşitlikler yardımı ile bulunur.

$S_{e}= \pm 2 \sqrt{\left(\frac{1}{n_{0}}\right) \sigma_{e}^{2}+\left(\frac{1}{n_{r}}\right) \sigma_{e}^{2}}$

\section{Hata kareleri toplam}

$\sigma_{e}^{2}=$

Hata için serbestlik derecesi

$\frac{1}{n_{0}}=\frac{1}{n}+\left[\frac{1}{n_{A_{i}}}-\frac{1}{n}\right]+\left[\frac{1}{n_{B_{i}}}-\frac{1}{n}\right]+\left[\frac{1}{n_{C_{i}}}-\frac{1}{n}\right]+\ldots \ldots$
Burada; Se güven aralığı, $\mathrm{n}$ yapılan toplam deney sayısı, $\mathrm{n}_{\mathrm{r}}$ teyit deneyinin tekrar sayısı ve $\mathrm{n}_{\mathrm{Ai}}, \mathrm{n}_{\mathrm{Bi}}, \mathrm{n}_{\mathrm{Ci}}, \ldots \mathrm{A}, \mathrm{B}, \mathrm{C}$ parametrelerinin i. seviyelerinin sayısıdır. Eğer tahmini hata, bu sınırlar dişında ise, bu modelin uygun olmadiğ 1 farz edilir(Phadke, 1989).

Doğrulama deneyi, kontrol parametreleri arasındaki etkileşimlerin varlığını tespit etmek için güçlü bir araçtır. Optimum koşullar altında tahmin edilen yanıt, gözlemlenen yanıtla eşleşmiyorsa, etkileşimlerin önemli olduğu anlamına gelir. Öngörülen yanıt, gözlemlenen yanıtla eşleşirse, etkileşimlerin muhtemelen önemli olmadığı ve toplamsal modelin iyi bir yaklaşım olduğu anlamına gelir(Phadke, Kackar, Speeney, \& Grieco, 1983).

\subsection{Parametrelerin genleşme oranı ve pişme kaybı üzerine etkileri}

$\mathrm{Bu}$ çalışmada kullanılan parametre sayısı 5 ve her bir parametre için seviye sayısı da 5 olarak alınmış ve $\mathrm{L}_{25}\left(5^{5}\right)$ Taguchi faktöriyel fraksiyonel deney tasarımı planı yapılmış olup, parametreler ve seviyeleri Tablo 3 de, deney planı ve araştırma sonuçları tablo 4 de verilmiştir.

Tablo 3. Tasarımin parametre ve seviyeleri (Table 3. Parameters and levels of design)

\begin{tabular}{|c|l|c|c|c|c|c|}
\hline \multirow{2}{*}{} & \multirow{2}{*}{ Parametreler } & \multicolumn{5}{|c|}{ Seviyeler } \\
\cline { 3 - 7 } & & 1 & 2 & 3 & 4 & 5 \\
\hline A & Organik Madde (\%) & 0 & 1 & 2 & 3 & 4 \\
\hline B & Ön Istma Sicaklığı $\left({ }^{\circ} \mathrm{C}\right)$ & 150 & 200 & 300 & 400 & 500 \\
\hline C & Ön Isıtma Süresi (Dakika) & 1 & 3 & 5 & 7 & 9 \\
\hline D & Sinterleme Sıcaklğı $\left({ }^{\circ} \mathrm{C}\right)$ & 1050 & 1100 & 1150 & 1200 & 1175 \\
\hline E & Sinterleme Süresi (Dakika) & 5 & 7 & 9 & 11 & 13 \\
\hline
\end{tabular}

Tablo 4. Tasarımın deney planı ve sonuçları (Table 4. Experiment plan and results of the design)

\begin{tabular}{|c|c|c|c|c|c|c|c|c|c|}
\hline Deney No & $\mathrm{A}$ & $\mathrm{B}$ & $\mathrm{C}$ & $\mathrm{D}$ & $\mathrm{E}$ & $\begin{array}{c}\text { Pişme } \\
\text { Kayb1 (\%) }\end{array}$ & $\begin{array}{c}\text { Genleşme } \\
\text { Oran1 (\%) }\end{array}$ & $\begin{array}{c}\text { Tane } \\
\text { Yoğunluğu }\end{array}$ & $\begin{array}{c}\text { Su emme } \\
\text { oran1 }\end{array}$ \\
\hline 1 & 1 & 1 & 1 & 1 & 1 & 27 & 0.670 & 1.532 & 13.00 \\
\hline 2 & 1 & 2 & 2 & 2 & 2 & 27 & 0.670 & 1.481 & 8.390 \\
\hline 3 & 1 & 3 & 3 & 3 & 3 & 23 & 0.670 & 1.469 & 7.640 \\
\hline 4 & 1 & 4 & 4 & 4 & 4 & 25 & 1.000 & 1.576 & 6.660 \\
\hline 5 & 1 & 5 & 5 & 5 & 5 & 27 & 0.670 & 1.369 & 7.190 \\
\hline 6 & 2 & 1 & 2 & 3 & 4 & 28 & 1.424 & 0.880 & 6.130 \\
\hline 7 & 2 & 2 & 3 & 4 & 5 & 29 & 1.424 & 0.713 & 3.730 \\
\hline 8 & 2 & 3 & 4 & 5 & 1 & 29 & 0.670 & 1.770 & 11.00 \\
\hline 9 & 2 & 4 & 5 & 1 & 2 & 26 & 1.000 & 1.890 & 12.14 \\
\hline 10 & 2 & 5 & 1 & 2 & 3 & 29 & 1.000 & 1.693 & 11.94 \\
\hline 11 & 3 & 1 & 3 & 5 & 2 & 30 & 1.953 & 0.810 & 9.830 \\
\hline 12 & 3 & 2 & 4 & 1 & 3 & 29 & 1.953 & 0.650 & 13.35 \\
\hline 13 & 3 & 3 & 5 & 2 & 4 & 29 & 0.670 & 1.620 & 9.590 \\
\hline 14 & 3 & 4 & 1 & 3 & 5 & 30 & 2.600 & 0.670 & 7.350 \\
\hline 15 & 3 & 5 & 2 & 4 & 1 & 27 & 0.670 & 1.559 & 5.440 \\
\hline 16 & 4 & 1 & 4 & 2 & 5 & 29 & 2.600 & 0.700 & 10.32 \\
\hline 17 & 4 & 2 & 5 & 3 & 1 & 30 & 4.291 & 0.640 & 9.400 \\
\hline 18 & 4 & 3 & 1 & 4 & 2 & 30 & 3.375 & 0.590 & 3.430 \\
\hline 19 & 4 & 4 & 2 & 5 & 3 & 27 & 1.0000 & 1.268 & 15.23 \\
\hline 20 & 4 & 5 & 3 & 1 & 4 & 28 & 1.0000 & 1.549 & 13.18 \\
\hline 21 & 5 & 1 & 5 & 4 & 3 & 28 & 4.2910 & 0.530 & 2.240 \\
\hline 22 & 5 & 2 & 1 & 5 & 4 & 23 & 2.5996 & 0.750 & 8.230 \\
\hline 23 & 5 & 3 & 2 & 1 & 5 & 30 & 1.1289 & 0.870 & 12.68 \\
\hline 24 & 5 & 4 & 3 & 2 & 1 & 27 & 0.6699 & 1.435 & 12.63 \\
\hline 25 & 5 & 5 & 4 & 3 & 2 & 27 & 0.6699 & 1.496 & 6.430 \\
\hline
\end{tabular}




\section{Araştırma Sonuçları ve Tartışma}

\section{1. Üretilen Genleşmiş Killer ve Özellikleri}

Çalışmalar sonucunda üretilen genleşmiş kil numuneleri şekil 3 de ve XRF ile yapılan kimyasal analiz sonuçları Tablo 5 de verilmiştir. Burada eser miktarda bulunan elementler analiz edilmemiştir. Ayrıca her bir deneyde elde edilen genleşmiş kilin tane yoğunluğu $530 \mathrm{~kg} / \mathrm{m}^{3}$ ila $1890 \mathrm{~kg} / \mathrm{m}^{3}$ aralığında değişmekte olup, optimum şartlardaki tane yoğunluğu $702 \mathrm{~kg} / \mathrm{m}^{3}$ olarak bulunmuştur.

Tablo 5. Çalışmada Üretilen Genleşmiş Kil'in Kimyasal Analizi (Table 5. Chemical Analysis of Expanded Clay Produced in the Study)

\begin{tabular}{|l|l|}
\hline Bileşik & Yüzde (\%) \\
\hline Ateşte kayıp: LOI & 0,09 \\
\hline $\mathrm{Fe}_{2} \mathrm{O}_{3}$ & 7,19 \\
\hline $\mathrm{CaO}$ & 3,09 \\
\hline $\mathrm{TiO}_{2}$ & 1,00 \\
\hline $\mathrm{Al}_{2} \mathrm{O}_{3}$ & 17,46 \\
\hline $\mathrm{SiO}_{2}$ & 63,60 \\
\hline $\mathrm{MgO}$ & 2,02 \\
\hline $\mathrm{K}_{2} \mathrm{O}$ & 2,92 \\
\hline $\mathrm{Na}_{2} \mathrm{O}$ & 0,86 \\
\hline
\end{tabular}

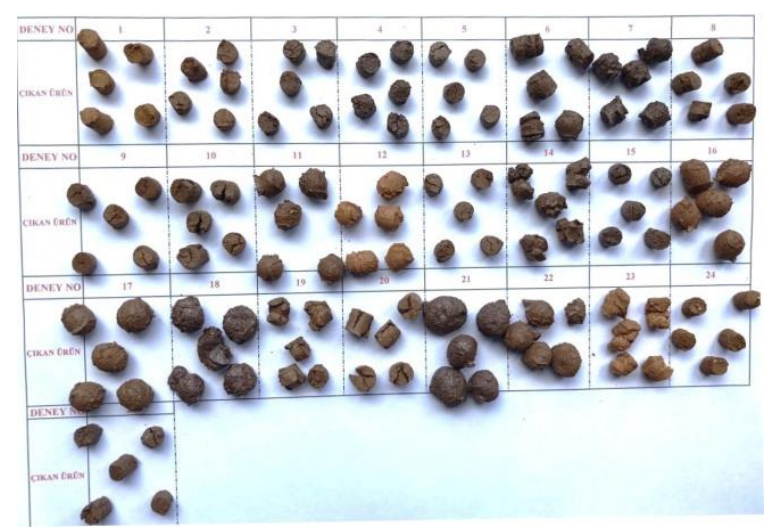

Şekil 3. Deneyler sonucunda üretilmiş genleşmiş kil bilyeleri

(Figure 3. Expanded clay balls produced as a result of experiments)

\subsection{Istatistiksel Hesaplamalar}

İstatistiksel hesaplamaların ve analizlerin yapılmasında MINITAB 17 paket programından yararlanılmıştır. Hafif genleşmiş kil üretiminde genleşme oranı ve pişme kaybını maksimum yapan parametre seviyelerinin bulunmasında (5) numaralı eşitlik kullanılmıştır. Genleşme oranı ve pişme kaybını maksimum yapan parametre seviyelerini tespit etmek için Tablo 4 deki değerler kullanılarak (5) nolu eşitlikten $\mathrm{SN}_{\mathrm{L}}$ değerleri bulunmuştur. $\mathrm{Bu} \mathrm{SN} \mathrm{SN}_{\mathrm{L}}$ değerleri yardımıyla parametre seviyeleri için marjinal ortalama performans istatistiği değerleri $\left(\mathrm{SN}_{\text {ort }}\right)$ hesaplanmış ve sonuçlar Şekil 4 ve 5 de grafik olarak verilmiştir. $\mathrm{SN}_{\text {ort }}$ değerini maksimum yapan parametre seviyelerine ait performans değerini tahmininde (7) nolu eşitlik kullanılmıştır.

Şekil 4 incelendiğinde $\mathrm{SN}_{\text {ort }}$ değerini maksimum yapan parametre seviyeleri, $\mathrm{A}_{4}, \mathrm{~B}_{1}, \mathrm{C}_{1}, \mathrm{D}_{4}$ ve $\mathrm{E}_{5}$ olduğu görülmektedir. Dolayısıyla genleşme oranını maksimum yapan parametre değerleri $A_{4}, B_{1}, C_{1}, D_{4}$ ve $E_{5}$ olacaktır. Buna göre optimum şartlar; organik madde miktarı için \%3, ön 1sıtma sıcaklığı için $150^{\circ} \mathrm{C}$, ön 1 sıtma süresi için 1 dakika, sinterleme sıcaklığ 1 için $1200^{\circ} \mathrm{C}$ ve sinterleme süresi için 13 dakika olarak bulunmuştur. Optimum şartlar altında tahmin edilen genleşme oranı 4,34 ve deneysel olarak bulunan değerde 4,32' dir.

Şekil 5 incelendiğinde $\mathrm{SN}_{\text {ort }}$ değerini maksimum yapan parametre seviyeleri, $\mathrm{A}_{4}, \mathrm{~B}_{1}, \mathrm{C}_{5}, \mathrm{D}_{2}$ ve $\mathrm{E}_{5}$ olduğu görülmektedir. Dolayısıyla pişme kaybını maksimum yapan parametre değerleri $\mathrm{A}_{4}, \mathrm{~B}_{1}, \mathrm{C}_{5}, \mathrm{D}_{2}$ ve $\mathrm{E}_{5}$ olacaktır. Buna göre optimum şartlar; organik madde mktarı için $\% 3$, ön 1 sitma sicaklığ 1 için $150^{\circ} \mathrm{C}$, ön ısıtma süresi için 9 dakika, sinterleme sıcaklığı için $1100^{\circ} \mathrm{C}$ ve sinterleme süresi için 13 dakika olarak bulunmuştur. Optimum şartlar altında tahmin edilen pişme kaybı \%31,6 ve deneysel olarak bulunan değerde \%30,3 olarak tespit edilmiştir. Ayrıca pişme kaybını, genleşme oranının optimum olduğu şartlar $\left(\mathrm{A}_{4}\right.$, $\mathrm{B}_{1}, \mathrm{C}_{1}, \mathrm{D}_{4}$ ve $\mathrm{E}_{5}$ ) için değerlendirdiğimizde tahmin edilen pişme kayb1 \%30,7 ve deneysel olarak bulunan değerde $\% 27,8$ olarak bulunmuştur.

Çalışmada kullanılan parametrelerin optimum seviyeleri ve bu seviyelere ait sayısal değerler ve alternatif çalışma şartları Tablo 6'de verilmiştir.

Tablo 6'de verildiği gibi genleşme oranını maksimum yapan parametre değerleri, pişme kaybı için de alternatif bir şart olarak da düşünülebilir. Burada pişme kaybı için 2.durum ile alternatif olan 3.durum hemen hemen aynı güven aralığı içinde kaldığından genleşme oranı için bulunan $\mathrm{A}_{4}, \mathrm{~B}_{1}, \mathrm{C}_{1}, \mathrm{D}_{4}$ ve $\mathrm{E}_{5}$ optimum şartları pişme kaybı içinde kabul edilerek, her iki performans değeri için optimum şart $\mathrm{A}_{4}, \mathrm{~B}_{1}, \mathrm{C}_{1}, \mathrm{D}_{4}$ ve $\mathrm{E}_{5}$ olarak alınabilir. $\mathrm{Bu}$ optimum şartlarda üretilen genleşmiş kil bilyelerinin tane yoğunluğu ve su emme yüzdeleri de araştırılmış olup, tane yoğunluğu $702 \mathrm{~kg} / \mathrm{m}^{3}$ su emme yüzdesi 6,45 olarak bulunmuştur.

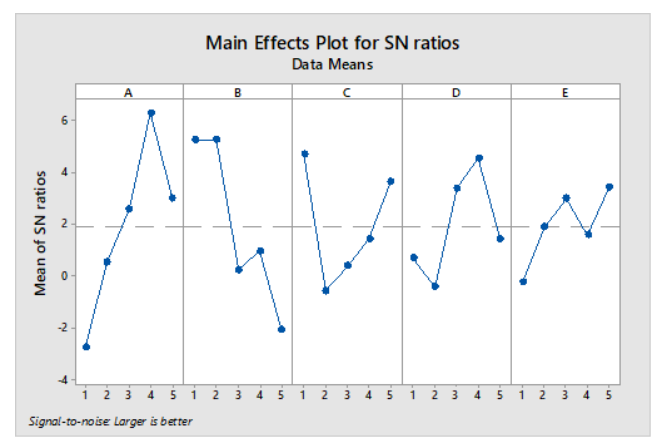

Şekil 4. Genleşme Oranı için parametre seviyelerine göre $\mathrm{SN}_{\text {ort }}$ değerleri (Figure 4. $\mathrm{SN}_{\text {ort }}$ values according to parameter levels for Expansion Rate)

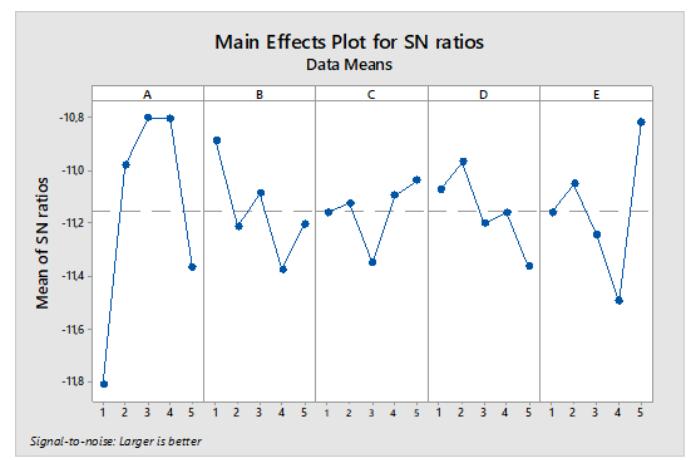

Şekil 5. Pişme kaybı için parametre seviyelerine göre $\mathrm{SN}_{\text {ort }}$ değerleri (Figure 5. $\mathrm{SN}_{\text {ort }}$ values according to parameter levels for Cooking loss) 
Tablo 6. Deneylerde optimum çalışma şartları, gözlemlenen ve tahmin edilen genleşme oranı ve pişme kaybı (Table 6. Optimum working conditions, observed and predicted expansion rate and cooking loss in the experiments)

\begin{tabular}{|c|c|c|c|c|c|c|}
\hline \multirow{3}{*}{\begin{tabular}{|l|} 
Parametreler \\
\end{tabular}} & \multirow{2}{*}{\multicolumn{2}{|c|}{$\frac{\text { Genleşme Oranı İçin }}{\text { 1.Durum* }}$}} & \multicolumn{4}{|c|}{ Pişme Kaybı İçin } \\
\hline & & & \multicolumn{2}{|c|}{ 2.Durum** } & \multicolumn{2}{|c|}{ 3. Durum*** } \\
\hline & Değer & Seviye & Değer & Seviye & & \\
\hline A: Organik Madde (\%) & 3 & 4 & 2 & 3 & 3 & 4 \\
\hline B: Ön Isıtma Sıcaklı̆̆ $1\left({ }^{\circ} \mathrm{C}\right)$ & 150 & 1 & 150 & 1 & 150 & 1 \\
\hline C: Ön Isıtma Süresi (Dakika) & 1 & 1 & 9 & 5 & 1 & 1 \\
\hline D: Sinterleme Sicaklğ $1\left({ }^{\circ} \mathrm{C}\right)$ & 1200 & 4 & 1100 & 2 & 1200 & 4 \\
\hline E: Sinterleme Süresi (Dakika) & 13 & 5 & 13 & 5 & 13 & 5 \\
\hline Gözlemlenen değer (\%) & 4,32 & & $\% 30,30$ & & $\% 27,80$ & \\
\hline Tahmin edilen değer (\%) & 4,34 & & $\% 31,63$ & & $\% 30,70$ & \\
\hline Güven aralığı (\%), Se & $3,22-5,46$ & & $28,45-34,81$ & & $27,52-33,88$ & \\
\hline
\end{tabular}

Tablo 7. Optimizasyon deneyi için varyans analizi (Genleşme Oranı için) - (Table 7. Analysis of variance for optimization experiment (for Expansion Ratio))

\begin{tabular}{|c|c|c|c|c|c|}
\hline Parametreler & $\begin{array}{c}\text { Serbestlik } \\
\text { Derecesi } \\
\mathrm{SD}_{\mathrm{i}}\end{array}$ & $\begin{array}{c}\text { Kareler } \\
\text { Toplamı } \\
\text { SS }_{\mathrm{i}}\end{array}$ & $\begin{array}{c}\text { Kareler } \\
\text { Ortalamas1 } \\
\mathrm{MS}_{\mathrm{i}}\end{array}$ & $F_{\text {Deneysel }}$ & $\begin{array}{c}\text { Etkinlik } \\
(\%)\end{array}$ \\
\hline \begin{tabular}{l|l} 
A & Organik Madde (\%)
\end{tabular} & 4 & 17,8160 & 4,45399 & 20,20 & 32,41 \\
\hline 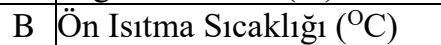 & 4 & 15,2114 & 3,80286 & 17,25 & 27,68 \\
\hline $\begin{array}{l}\text { C Ön Isttma Süresi (Dakika) }\end{array}$ & 4 & 11,7257 & 2,93141 & 13,30 & 21,34 \\
\hline \begin{tabular}{l|l}
$\mathrm{D}$ & Sinterleme Sicaklğ $1\left({ }^{\circ} \mathrm{C}\right)$ \\
\end{tabular} & 4 & 8,7973 & 2,19933 & 9,98 & 16,01 \\
\hline \begin{tabular}{|l|l} 
E & Sinterleme Süresi (Dakika)
\end{tabular} & 4 & 1,4143 & 0,35356 & 1,60 & 2,57 \\
\hline \begin{tabular}{l|l} 
Hata \\
\end{tabular} & 29 & 6,3938 & 0,22048 & - & - \\
\hline Toplam & 49 & 61,3585 & - & 62,33 & - \\
\hline
\end{tabular}

Tablo 8. Optimizasyon deneyi için varyans analizi (Pişme Kaybu için) - (Table 8. Analysis of variance for optimization experiment (for Cooking Loss))

\begin{tabular}{|c|c|c|c|c|c|}
\hline Parametreler & $\begin{array}{c}\text { Serbestlik } \\
\text { Derecesi } \\
\mathrm{SD}_{\mathrm{i}}\end{array}$ & $\begin{array}{l}\text { Kareler } \\
\text { Toplamı } \\
\text { SS }_{\mathrm{i}}\end{array}$ & $\begin{array}{c}\text { Kareler } \\
\text { Ortalamas1 } \\
\text { MS }_{\mathrm{i}}\end{array}$ & $\mathrm{F}_{\text {Deneysel }}$ & $\begin{array}{c}\text { Etkinlik } \\
(\%)\end{array}$ \\
\hline \begin{tabular}{l|l} 
A & Organik Madde (\%)
\end{tabular} & 4 & 72,992 & 18,2479 & 10,25 & 59,56 \\
\hline $\mathrm{B}$ Ön Isıtma Sicaklığ $1\left({ }^{\circ} \mathrm{C}\right)$ & 4 & 13,233 & 3,3083 & 1,86 & 10,81 \\
\hline C Ön Isıtma Süresi (Dakika) & 4 & 4,878 & 1,2194 & 0,68 & 3,95 \\
\hline \begin{tabular}{l|l}
$\mathrm{D}$ & Sinterleme Sicaklğ $1\left({ }^{\circ} \mathrm{C}\right)$
\end{tabular} & 4 & 7,809 & 1,9523 & 1,10 & 6,39 \\
\hline \begin{tabular}{|l|l} 
E & Sinterleme Süresi (Dakika)
\end{tabular} & 4 & 23,618 & 5,9044 & 3,32 & 19,29 \\
\hline Hata & 29 & 51,639 & 1,7807 & & \\
\hline Toplam & 49 & 174,168 & & & \\
\hline
\end{tabular}

Parametrelerin etkin olup olmadikları, deneysel olarak

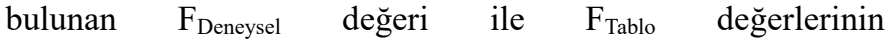
karşılaştırılmasıyla tespit edilmiştir. Eğer $F_{\text {Deneysel }}>F_{\text {Tablo }}$ ise, ilgili parametre performans değeri üzerinde etkindir. Ĕ̆er $\mathrm{F}_{\text {Deneysel }}<\mathrm{F}_{\text {Tablo }}$ ise parametre performans değeri üzerinde etkin değildir. Tasarım deneyleri için yapılan varyans analizleri genleşme oranı için Tablo 7'de, pişme kaybı için ise Tablo 8 'da verilmektedir.
Tablo 7 incelendiğinde sinterleme süresi dışındaki tüm parametrelerin FDeneysel değerlerinin $\mathrm{F}_{\text {Tablo değerlerinden büyük }}$ olduğu görülmektedir. $\mathrm{Bu}$ da optimizasyondaki seçilen sinterleme süresi dışındaki tüm parametrelerin, performans değeri üzerinde oldukça etkili olduğu anlamına gelmektedir. Her bir parametrenin etkinliği $\mathrm{F} / \Sigma \mathrm{F}$ denklemden yaklaşık olarak belirlenmiştir. (Levent, Kaya, Kocakerim, Yiğit, \& 
Küçük, 2007). Burada en etkin parametrenin organik madde miktarının olduğu açıkça görülmektedir.

\section{Sonuç}

Mevcut çalışmadan çıkan başlıca sonuçlar şunlardır:

Hafif Genleşmiş kil üretiminde genleşme oranı üzerinde etkili olan parametreler etkinlik düzeyine göre sirasıyla organik madde, ön 1sıtma sıcaklığı, ön 1sıtma süresi, sinterleme sıcaklığıdır. Sinterleme süresinin etkin olmadığ söylenebilir.

Hafif Genleşmiş kil üretiminde pişme kaybı üzerinde etkili olan parametreler ise etkinlik düzeyine göre sirasıyla organik madde, sinterleme süresi, ön 1sıtma sıcaklığ1, sinterleme sıcaklğ 1 ve ön 1sitma süresidir. Ön 1sitma süresi \%99 güven seviyesinde etkin olmayıp, \%95 güven seviyesinde ise çok az etkilidir.

Seçilen parametre değerleri dahilinde optimum koşullar, organik madde miktarı için \%3, ön 1sıtma sıcaklığ ön 1sıtma süresi için 1 dakika, sinterleme sıcaklığı için $1200^{\circ} \mathrm{C}$ ve sinterleme süresi için 13 dakikadır. Bu koşullar altında genleşme oranı 4,32, pişme kaybı $\% 27,80$, tane yoğunluğu 702 $\mathrm{kg} / \mathrm{m}^{3}$, su emme yüzdesi 6,45 olarak bulunmuştur (Tablo 6).

Öngörülen ve gözlenen değerler birbirine çok yakındır ve toplamsal modelin üretim sürecinin çeşitli parametrelere bağımlılı̆̆ını açıklamak için yeterli olduğu sonucuna varılabilir.

Laboratuvar ortamında Taguchi yöntemi ile belirlenen optimum koşullar gerçek üretim ortamlarında da tekrarlanabilir olduğundan; bu çalışmanın bulguları endüstriyel ölçekte işleme için çok faydalı olabilir.

\section{Teşekkür}

$\mathrm{Bu}$ çalışmanın yapılmasında malzeme temini sağladığı ve laboratuvar imkânlarını sunduğu için Söğüt Toprak Madencilik şirketine teşekkür ederiz.

\section{Kaynakça}

Ahmad, M. R., Chen, B., \& Farasat Ali Shah, S. (2019). Investigate the influence of expanded clay aggregate and silica fume on the properties of lightweight concrete. Construction and Building Materials, 220, 253-266. doi:https://doi.org/10.1016/j.conbuildmat.2019.05.171

Arı̈z, Karasu, B., Kılınç, K., Kaya, G., Arslan, G., Tuncan, M., Tuncan, A. \& Kivrak, S. (2007). Production of Expanded Clay Aggregate by The Use of Coal. Paper presented at the The IV. Ceramic, Glass, Enamel, Glaze and Pigment Seminar with International Participation (SERES 2007), 1054-1062, Eskisehir, Turkey.

Bogas, J. A., Gomes, A., \& Pereira, M. F. C. (2012). Selfcompacting lightweight concrete produced with expanded clay aggregate. Construction and Building Materials, 35, 1013-1022.

doi:https://doi.org/10.1016/j.conbuildmat.2012.04.111

Devecioğlu, A. G. (2012). Kitre Katkılı Genleştirilmiş Kil Agregalı Betonların Isıl Ve Mekanik Özelliklerinin Analizi. (Doktora Tezi), Fırat Üniversitesi, Fen Bilimleri Enstitüsü, Elazığ, Türkiye.

Dilli, M. E., Atahan, H. N., \& Şengül, C. (2015). A comparison of strength and elastic properties between conventional and lightweight structural concretes designed with expanded clay aggregates. Construction and Building Materials, 101, 260-267.

doi:https://doi.org/10.1016/j.conbuildmat.2015.10.080

Gündüz, L., Kalkan, Ş. O. \& Özgüven, A. . (2020). Genleşmiş Kil Agregaların Teknik Özelliklerinin Karşılaştırılması Üzerine Bir Çalışma Ankara Kalecik Bölgesi Örneği. Hazır Beton, 157, 65-72.

Gündüz, L., Şapçı, N., Bekar, M. (2006). Utilization of expanded clay as lightweight aggregate. Journal of Clay Science and Technology, 1(2), 43-49.

Güneş, O. (2019). Genleştirilmiş Kil Agregası İle Taşıyıcı Hafif Beton Üretimi. (Yüksek Lisans Tezi), Dumlupınar Üniversitesi, Fen Bilimleri Enstitüsü İnşaat Mühendisliği Anabilim Dalı, Kütahya.

Küçük, Ö., Kocakerim, M.M., Çopur, M. \& Yartaş1, A. (2005). Optimization Of Dissolution Of Ulexite In $\left(\mathrm{NH}_{4}\right)_{2} \mathrm{SO}_{4}$ Solutions. Canadian Metallurgical Quarterly, 44(1), 53-58. doi:https://doi.org/10.1179/cmq.2005.44.1.53

LECAT. (2021). Söğüt Toprak Madencilik A.Ş. Retrieved from https://lecat.com.tr/lecat-nedir

Levent, M., Kaya, Ö., Kocakerim, M., Yiğit, V., \& Küçük, Ö. (2007). Optimization of desulphurization of Artvin-Yusufeli lignite with acidic hydrogen peroxide solutions. Fuel, 86(7), 983-992. doi:https://doi.org/10.1016/j.fuel.2006.10.010

Montgomery, D. C. (1991). Design and Analysis of Experiments, . ABD: John Wiley \& Sons Inc.

Nkansah, M. A., Christy, A. A., Barth, T., \& Francis, G. W. (2012). The use of lightweight expanded clay aggregate (LECA) as sorbent for PAHs removal from water. Journal of Hazardous Materials, 217-218, 360-365. doi:https://doi.org/10.1016/j.jhazmat.2012.03.038

Onatskiy, S. P. (1987). Expanded Clay Production: 3rd ed., rev. and add, M., Stroyizdat Publ., 1987, p. 333 (in Russian).

Ozguven, A., \& Gunduz, L. (2012). Examination of effective parameters for the production of expanded clay aggregate. Cement and Concrete Composites, 34(6), 781-787. doi:https://doi.org/10.1016/j.cemconcomp.2012.02.007

Özgüven, A. (2009). Genleşen Kil Agrega Üretimi Ve Endüstriyel Olarak Değerlendirilmesi. (Doktora), Süleyman Demirel Üniversitesi, Fen Bilimleri Enstitüsü, Maden Mühendisliği. (237301)

Phadke, M. S. (1989). Quality engineering using robust design, . Prentice Hall, New Jersey, 61-292.

Phadke, M. S., Kackar, R. N., Speeney, D. V., \& Grieco, M. J. (1983). Off-line quality control in integrated circuit fabrication using experimental design. The Bell System Technical Journal, 62(5), 1273-1309. doi:10.1002/j.15387305.1983.tb02298.x

Pioro, L. S., \& Pioro, I. L. (2004). Production of expanded-clay aggregate for lightweight concrete from non-selfbloating clays. Cement and Concrete Composites, 26(6), 639-643. doi:https://doi.org/10.1016/S0958-9465(03)00103-3

Rashad, A. M. (2018). Lightweight expanded clay aggregate as a building material - An overview. Construction and Building Materials, $170, \quad 757-775$. doi:https://doi.org/10.1016/j.conbuildmat.2018.03.009

Subaşı, S. (2009). Productıon of structural lightweight concrete with expanded clay aggregate. J. Fac. Eng. Arch. Gazi Univ, 24(3), 559-567.

Şirvancı, M. (1997). Kalite için deney tasarımı "Taguchi Yaklaşımı". İstanbul: Literatür Yayıncılık. 
Taguchi, G. (1987). System of Experimental Design, Quality Resources: (Vol. 1). New York.

Vašina, M., Hughes, D. C., Horoshenkov, K. V., \& Lapčík, L. (2006). The acoustical properties of consolidated expanded clay granulates. Applied Acoustics, 67(8), 787-796. doi:https://doi.org/10.1016/j.apacoust.2005.08.003 